\title{
El Impacto Psicológico de la Ciencia Atómica sobre el Arte Moderno
}

\author{
Por Felix Marti $Y_{\text {BANẼEZ }}$
}

\section{LAS BASES FILOSOFICASS DE LA NUEVA CIENCIA ATOMICA \\ 1 - El nuevo organismo ideológico del Siglo XX}

El año mil novecientos es una fecha decisiva en la historia del pensamiento. En dicho año, comienzan a elevarse sobre el horizonte intelectual del nuevo siglo una serie de ideas nuevas que difieren radicalmente de las que formaron el subsuelo filosófico-científico del siglo XIX. Media centuria más tarde, tales conceptos se han integrado en un organismo ideológico peculiar laecruestro siglo.erso"

El hombre está demostrando hoy día el tremendo valor de las ideas, al atestiguar con las nuevas teorías físicas que es posible encadenar hasta el paso de los astros más remotos a las ecuaciones elaboradas por un cerebro humano en la soledad de un laboratorio. Igual que la teoría copernicana fué el principio educador de la Edad Maderna, las ideas del universo cuatridimensional, el espacio curvilíneo y el orbe finito, unidas a la actual autonomía de cada disciplina científica, están grabando una cicatriz indeleble sobre la faz histórica de nuestro siglo.

El nuevo organismo de ideas del siglo $\mathrm{XX}$ está tiñendo de sus colores todas las actividades humanas, desde los más humildes quehaceres hasta el pensamiento científico y la obra artística, como el sol colorea de variantes tornasoles los objetos de un paisaje al compás de su ascensión por la comba celeste.

El año 1900 marca el comienzo de una crisis histórica en la evolución del pensamiento científico. Es una fecha que inicia un momento 
histórico comparable al de 1300, la "hora de Dante", en la que se creó una "figura de mundo" que perduró durante varias generaciones. A un sistema de convicciones científicas ha sucedido otro sistema, y no por continuidad sino por salto, lo que acentúa su dramatismo.

La crisis del pensamiento científico, que ha traído a rastras otra crisis en el pensamiente artístico, ha significado dejar sin universo sóiido, trastocar las convicciones del hombre actual, aislándole en un vacío, al derrocar las ideas sobre las que el mundo del siglo XIX se sustentaba. Mas el pensamiento - al igual que el cuerpo humanotiene horror al vacíc, y tiende en el acto a rellenarlo de contexturas culturales que le den un nuevo suelo sobre el que posar sus plantas inciertas, como el organismo rellena de tejido conjuntivo cuclquier hueco, accidental u operatorio, producido en sus intimidades.

En la vida moderna, la Ciencia adquiere el carćster de víscera suprema cuya palpitación anima otros órganos artísticos o filosóficos, más adiposos o conjuntivos, mencs vitales que el pensar científico. Esbozar las líneas sencillas pero gigantes del pensamiento científico moderno, equivale a trazar el marco dentro del cual se pueden encajar e interpretarse las demáe formas de vida actual, y entre ellas, especialmente, la actividad pictórica que denominamos "arte moderno".

A comienzos de siglo se creía que todo se había inventado ya. Los primeros años de nuestro siglo fueron de mera cosecha y explotación tecnalógica. Desde 1880 Se venían usandalos motores cle combustión interna que hiciēron luego posible el desarrollo de autos y aviones. Las ondas de radio se descubrieron por Herz en 1887; en 1898 se envió el primer radiograma desde la isla de Wight; y en 1878 se inauguró en New Haven, Connecticut, el primer teléfono públicc. La teoría de los gérmenes se conocía desde 1860, y gracias a ella el hombre fué eliminando esos parásitos externos que fueron las bestias prehistóricas. Mas si un hombre de 1900, que hubiera vivido sumido en profunda letargo, aislado del trascurso de esta media centuria, despertara en nuestro tiempo y mirase en derredor suyo, se asombraría del cambio acaecido en el mundo circundante.

¿Es que ha cambiado el universo? No; el universo no ha variado a lo largo de la Historia, lo que cambia es nuestra actitud mental ante el mismo. La vida ha existido hace 1.200 millones de años, el hombre ha existido desde hace un millón de años aproximadamente, ha usado su cerebro para crear pragreso desde hace 50.000 años, ha podido escribir sus pensamientos desde hace unos 6000 años, y creado civilización desde hace unos 400 años; pero solamente ha usado la cien- 
cia como factor educaliva de su vida desde hace unos 300 años. Desde entonces, la misión de la Ciencia ha sido efectuar un inventario del universo para el ser humano, revelarle el sistema de posibilidades disponibles, y el modo de utilizarlas para su propio mejoramiento $c$, a veces. para su propia destrucción.

Acaso ninguna otra ciencia como la Física ha influenciado do modo tan profundo el pensamiento humano. Desde aquella tremenda crisis histórica que llamamos el Renacimiento, la Física ha intentado descubrir las leyes que gobiernan los objetos materiales en el tiempo y el espacio. Hace apenas un siglo que la Física estaba sometida a las leyes de la causalidad, que de un moda inmutable regían el universo. Mas el desarrollo de las Matemáticas, que son la patria de elección del genio, ha revolucionado la Física del siglo XX, que representa un momento álgido en la historia de la Civilización. La nueva Física borbotea de genios, como burbujeaba de artistas la pintura florentina del Quatrocento.

El cambio de nuestra actitud mental ante el universo ha significado un notable progreso del hombre, que ha adelantado menos en la Ciencia por los descubrimientos que por su concepción de nuevers relaciones entre ideas diferentes, por su aptitud de ver los viejos fenómenos físicos y mentales con una óptica flamante, usando la regla del matemático alemán del siglo pasado, Karl Jacobi : "Mann muss immer umkehren" (una debel invertir las cosas)..

Ese espíritu dej dagnueva investigación científica ha hecho que los conceptos básicos en los que se sustentó el universo hasta 1900. tales como los del espacio y el tiempo, la inercia, energía y simetría, hayan sido conmovidos por un demonio que ha sacudido la Física, derrocando la noción aristotélica del movimiento natural y convirtiendo aquellas ideas en nociones como las de las intervalos de espacio-tiempo, la curvadura del universo y las vorágines atómicas.

\section{2 - Concepio y raíces histórico-filosóficas de la ciencia atómica}

Por "ciencia atómica" entenderemos el nuevo pensamiento físicomatemático iniciada a comienzos de siglo, sobre el que se han sustentado los cambios más revolucionarios acaecidos en la historia del pensamiento humano.

En la mente del hombre de la calle se acostumbra a asociar la idea de "ciencia atómica" con la de su espectacular demostración en las tres simbólicas explasiones que durante la pasada guerra mundial 
sacudieron el planeta, y marcaron un avance supremo on la ciencia y el arte de matar. Mas en nuestro estudio prescindiremos de la bomba atómica, considerándola solamente como una aplicación "práctica" - ¡Dante no vió nada! - del pensamiento físico-matemálico que ha gobernado el desarrollo de la energía atómica.

Lo que nos importa es bosquejar el perfil filosófico de los principales adelantos del pensamiento físico y matemático en los últimos cincuenta años, y estudiar sus repercusiones sobre otras manifestaciones intelectuales del hombre de nuestro tiempo.

El hombre ha necesitado tantos años para llegar a desarrollar sus ideas sobre la estructura alómica de Ia materia, porque las concepciones del átcmo estuvieron desde su comienzo en aparente contradicción con el testimonio de nuestros sentidos. La vista y el tacto nos dicen en todo momento, que cuanto nos rodea, y nuestro propio cuerpo, son materias sólidas y continuas."

La idea de que esa materia ni es sólida ni continua, resulta, aún en 1951, tan fantástica para ciertas gentes como en el siglo $V$ antes de Cristo lo fué aún para las personas más inteligentes, cuando los filósofos griegos emitieron por vez primera la teoría de la estructura atómica de la materia. Tanto fué así, que cuando un filósofo andariego llamado Demócrito de Abdera dijo, en el año 420 a. d. C., que las cosas estaban formadas por un número infinito de álomos invisibles, sepcirados unos de otros por amplios espacios y en perenne novimientc, los hombres sensatos le tomarono poe lod6, yn lel iaconsejaron que se hiciera tratar por un cierto médico vecino suyo llamado Hipócrates.

Demócrito, personaje fábuloso y legendario, adoptó la teoría del atomismo de su maestro, - y, según algunos, verdadero creador de la teoría- Leucipa, quien estableció que la "esencia" de la materia que forma el agua, o sean las partículas inmutables cuyos cambios se refieren solamente a sus relaciones espaciales, no varía cuando ésta se convierte en hielo y vuelve luego a convertirse en agua (I). Su discípulo Demócrito, un día, en la playa tomando en una mano un puñado de arena y en la otra un poco de agua del mar, explicó a sus discípulos

(1) Su doctrina ha resucitado en cierto modo en el titomo actual de Heisenberg, como la de Demócrito lo hizo en el átomo, más determinista, de hace treinta años, de Rutheford $y$ Bolır. Demócrito creó tu torno a su idea del átomo ina Cosmología basada en el atomismo, que fué combatida en sus escritos por Platón y Ioracio. Iucrecio, en el año 75 a. d. Cristo, y Aristóteles, contribuyeron a expandir y clesarollar las tro rías atómicas, naciendo de la obra aristotélica los fundamentos de la Física ciéntífica. 
que la materia, como la arena, estaba formada de minúsculos granitos a los que llamó "átomos" (o sea, indivisibles), y que la estructura de la materia no era continua, como, en cpariencia, lo era el agua contenida en su mano. A Demócrito se debió también la idea de que la luz emitida por la Vía Láctea procedía de innumerables estrellas invisibles a simple vista, hipótesis que Galileo confirmaría dos mil años más tarde mirando con su telescopio las estrellas del cielo de Venecia.

Un siglo más tarde, Epicuro de Samcis continuó esta teoría estableciendo la existencia de átomos dotados de "libertad interior o libre albedrío", que les permitía separarse de las rutas prefíjadas que tenían, según Demócrito.

Mas hizo falta el transcurso de unos mil ochacientos años para que, al hacerce la Química una disciplina científica, se confirmara el atomismo, al resultar la estructura atómica la única que permitía explicar las leyes gobernantes de las reacciones químicas. Dalton en 1808 y Avcgadro en 1811-17, confirmaron la estructura atómica molecular de la materia; Lavoisier, en el siglo: XVIII, descubrió la ley de la conservación de la materia, y Mayer y Helmholtz la de la energía, remachando así las doctrinas del atomismo, cuya plena confirmación vino en nuestro tiempo cuando se hizo posible el contaje de los átomos.

En Biología, la estructura atómica se confirmó también al establecerse que la transformación de unas moléculas en otras en los procesas metabólicos de la materia orgánica, se realiza liberando o absorbiendo energía, como sucede en das reacciones físicas desarrolladas en la materia inanimada. Con el advenimiento de estas doctrinas, el mundo sigue siendo una máquina, pero de ruedecillas mucho más minúsculas que antaño.

En los siglos XVII y XVIII impera el pensamiento mecanístico de que el mundo inanimado es un sistema autoperpetuante, en el que todos los cambios se verifican con arreglo a leyes naturales. El pensamiento copernicano reemplaza científicamente a las viejas ideas simbolizadas en la concepción de Dante de que la tierra es centro del universo, con diez esferas circundándola.

No obstante, aun en una hora tan grávida de trascendencia científica como la de Newton, la Ciencia intentó demostrar que Dios es el creador de las leyes de la gravitación y demás leyes físicas del universo. El papel del hombre eh el universo a la vez se elevó y degradó en esta suprema tentativa de concilicición entre la ciencia y la fé. En ese eterno conflicto entre la tradición y la observación, puede resumirse la historia del pensamiento humano. 
Para los físicos del siglo XIX, el universo estaba edificado sobre el andamiaje de las leyes newtonianas del movimiento. No se contaba con la idea de fuerza, sino con la de meros cambios materiales. La materia se creía inmutable. Lo más que se llegaba a aceptar era que la combustión liberaba energía, aunque no se creía que la materia se transformase en energía. Los elementos químicos se consideraban indestructibles y no se creía que un átomo pudiera transformarse en otro, como en el viejc ensueño romántico de los alquimistas. Solamente la imposibilidad de poder explicar fenómenos como la perfecta estabilidad atómica, los rayos X y la radioactividad, indicaban que la F'ísica clásica, mecánica y determinística, era incapaz de interpretar todos los fenómenos del universo (2).

\section{3 - La teoría de los quanta, piedra miliar de la Física atómica}

En 1900, Max Planck, en Berlin, se convenció de que el espectro de radiación de los cuerpos oscuros no podía explicarse por los principios de la mecánica clásica. En su lugar, pensó que acasó la energía irradiada no se emitía continuamente sino en quantas o cantidades

(2) En r 900 cuando aún se aceptaba la teoría del espacio y el tiempo de Newton, para explicar la propagación delas ondas de fuz a fravés de los espacios interestelares, se concebia como vehícuio subsinciai un "̈eter, absolutamente en reposo". En dicho

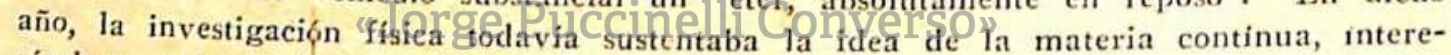
sándose en la conducta de la materia en bruto e ignorando su estructura atómica. Los resultados tecnológicos fueron formidables en los campos de la termodinámica, hidrodinámica, electricidad, aerodinámica, acústica $y$ ondas ultrasónicas. La más notable diferencia entre las físicas de 1900 y 1950 , es la completa victoria actiral de los atomistas, que han resucitado las vicjas especulaciones de los alquimistas medioevales.

En 1900 comenzó la historia del átomo, cuyas piedras miliarcs fueron el descubrimiento del electrón (1894) por J. J. Thomson, Cl de los rayos X (1895) por W. K. Roentgen, el de la radioactividad (1896) por Henny Becquerel, el de los clementos radioactivos - radio y torio- por Pierre y Marie Curie (1898), y la identificación de los núcleos atómicos y rayos alfa y beta, desde 1902 , por la brillante investigación de Rutherford y su escuela.

Hoy sabemos que el átomo está formado de nucleones, o sea, protones de carga eléctrica positiva, de neutrones sin carga eléctrica, y de electrones de carga negativa, I.800 veces más ligeros que los nucleones. El núclco del átomo, un conglomerado de protones y neutrones, es sólo de una millonésima de millonésima de milímetro de diámetro, $y$ en su derredor se mueven los electrones, como los planetas alrededor del sol, en órbitas cuyos diámetros son ro.00o veces más largos que los del núcleo. Cada átomo, tiene exactamente tantos electrones como protenes o cargas positivas en su núcleo, dependiendo de estos últimos todas sus propiedades quimicas, y casi todas las físicas. 
finitas, proporcionales en cada caso a la frecuencia de las radiaciones, expresándose dicha frecuencia en una cifra que se llamaría más tarde la constante de Planck (3).

Esta tecría se recibió con gran escepticismo, pues parecía raro retornar al viejo concepto corpuscular de la luz, abandonando la teoría ondulatoria, hasta que Einstein demastró esta teoría al aplicarla a la emisión de electrones por los metales, y a las propiedades térmicas de los cristales.

La intuición genial de Max Planck fué recurrir a la hipótesis de que la emisión de luz por cuerpos radiantes se hacía por minúsculos estallidos indivisibles, lo que entonces resultaba tan fantástico como decir que una bala avanzaba en su trayectoria por pequeños saltos (4).

Esta hipótesis, emitida con la modestía característica del genio, que permanecería sumergida en el fondo del proceloso océano de teorías espectaculares aparecidas a comienzos de siglo, representaba la sustitución de los átomos, demasiado vastos para ser considerados como las piedras angulares del universo, por los infinitamente menores quantum o saltos de energía de Planck.

El quantum nació así como la más pequeña acción posible puesta en juego en un fenómeno físico. Fué una audaz concepción, que más tarde se agigantaría y convertiría en una verdadera insurrección quántica que obligaría a reemplazar las rígidas leyes de la física antigua por leyes de probabilidad. CPlanck había demostrado, en un comienzo sólo para una selecta élite de físicos y matemáticos y, al correr de los años, ante el mundo entero, que el concepto filosófico de la continuidad en el universo, no tenía más que una apariencia estadística. Las teorías clásicas eran la confirmación de lo imperfecto de nuestros sentidos, que creaban la idea de continuidad en un universo en donde todo era discontinuo y espasmódico.

(3) Al degarrollar sus ecuaciones, Max Planck observó que las mismas podían describir las emisiones de energía radiante, mediante saltos -a los que denominó quanla- que variaban con la frecuencia de la luz. Su ecuación, ya famosa en la historia de la Ciencia, fué la de que "un quantum de energía iguala "h" veces la frecuencia de la luz". La "h", era la llamada constante de Planck, equivalente a $0,000.000 .000 .000$. c00.000.000.000.006.6.

(4) A la teoría de la discontinuidad de la energía, agregó Planck la idea de que así como los átomos difieren según la clase de materia de donde proceden, siendo unos más pesados que otros, también los "átomos" de energía son distintos unos de otros, según sea su fuente de procedencia. La magnitud o quantum de la energía de radiación era directamente proporcional a la frecuencia de la radiación. La constante de Planck no resultó ser un gránulo de energía, sino un yuantum de momento cinética. 
La teoría de Planck representa, a nuestro entender, la piedra angular de toda la Ciencia atómica de nuestro siglo, y su formulación fué acaso la hora más crucial en la historia de la Ciencia. Todavía no ha trascendido a las masas su valor, reivindicando para su creador una merecida gloria, lo que confirma una vez más que no siempre los laureles van a ceñir la frente del verdadero vencedor de los Maratones en pos de la Verdad científica.

La teoría de los quanta estableció que no sólo la materia era discontinua, sino también la energía (5). En su teoría se contenía el gérmen de la teoría de la relatividad. En el atonismo de la energía figuraba el del tiempo, pues la nueva visión del universo no podía ser estática sino dinámica. Fué una lástima que los quantas se descubrieran cinco años antes de que Einstein formulara su teoría de la relatividad, pues de haber sucedido al revés no hubiera sido difícil concebir que si materia y energía son simples facetas de una misma realidad, si la materia era discontinua, también debía serlo la energía. El velo que cubría esta elementalísima verdad no se descorrió ante los ojos de los investigadores, porque en 1900 no se conocía la relatividad, y las ideas de Planck fueron consideradas por muchos como la simple expresión Le un pensamiento empírico. Planck tuvo que aguardar más de un cuarto de siglo para ver germinar el fruto de su concepción, que transformaría la estructura del universo en el cerebro del hombre de ciencia actual (6).

La teoría de los quanta redujo la materia, considerada sólida hasta entonces, a "ondas de probabilidad", idea de la que nacería, cuarenta y cinco años más tarde, la bomba atómica. El público no se apercibió en un comienzo de la trascendencia de la teoría, acaso por lo difícil que aun resulta a la mentalidad popular cuanto se expresa en términos de alta y pura matemática y no tiene una simbólica drama-

(5) La teoría de los quanta explicó el enigma de la estabilidad atómica, y permitió interpretar los sistemas periódicos de elementos, más ambas teorías de la luz siguicron en boga : la ondulatoria y la corpuscular. La fórmula de Planck fué : $\mathrm{E}=\mathrm{hv}$ (el quantum de energía iguala la constante de tiempo-energía de Planck), confirmíndose por Broglic que 'las ondas se comportan como partículas y viceversa. La unidad de ambos aspectos de la materia $y$ la luz se formuló matemáticamente por Heisenberg, Born, Jordan, Schrodinger.

(6) En 19r3, Niels Bohr aplicó con éxito la teoría de lơs quanta a los fenímenos del átomo, describiéndolo como un sol en miniatura rodeado de planetas electrónicos que saltan como ondas de uná a otra órbita, emitiendo quantas de luz sin obedecer leyes regulares. 
tización gráfica. Mas la revolución científica ya estaba en marcha. La Física había sido sacudida como por un cataclismo sísmico hasta sus más sólidos cimientos.

\section{4 - Sentido filosófico de la teoría de la relatividad de Einstein}

El siguiente capítulo de la nueva Física comienza con la inicial miniada en oro de las teorías de Einstein, quien redujo a la nada los viejos conceptos de espacio y tiempo mediante el simple argumento de que la concepción de acontecimientos absolutamente simultóneos en diferentes lugares, no tiene significado físico, porque la velocidad de las señales más veloces (luz) es la misma para todos los observadores, sea cual fuere su movimiento (7).

La aportación de Einstein al pensamiento atomístico moderno ha sido revolucionar las ideas sobre la naturaleza, el espacio y el tiempo, como la teoría de los quanta revolucionó las ideas sobre la materia y energía. La Física del siglo pasado era materialista y mecanicista. Hoy, la materia ya no es sólida, sino que es un hueco en el espaciotiempo, una mañara de electricidad, una onda de probabilidad ondulando en la nada, una proyección de la conciencia.

Einstein ha cambiado, junto con la Matemática, el siglo XX. En vez del espacio plano euclidiano ha creado el espacio curvo, cuya curvadura varía de uno a otro punto, y cuya intensidad en un punto mide la intensidad del campo gravitatorio en el mismo. Mas la base filosófica fundamental de la teoría einsteniana, es el haber creado una teoría, mal llamada de la relatividad, porque lo relativo en ella son los

(7) La ley einsteniana más importante es la que establece la equivalencia entre masa $y$ energía : $E=m c 2$, sindo $c$ la velocidad de la luz.

Posteriormente, en 1908, Minkowski estableció la teoría matemátioa de que espacio y tiempo se fundían en una extensión cuatridimensional, en la que cada punto representa un "aconfecimiento", y en la que se mantiene la generalización de la geometría ordinaria euclidiana.

En 1915 Einstein extendió la teoría de la relatividad a los sistemas acelerados, obteniendo una teoría de los campos de gravitación que contenía la teoría newtoniana como su primera aproximación. Su principal acierto fué la predicción y comprobación, durante el eclipse total de 1918 , de que la luz que llegaba a nosotros procedente de las estrellas se desviaba al pasar cerca del sol. Los astrónomos desarrollaroni la idea de la expansión del universo, basándose en el descubrimiento de que kas distantes nebulosas o galaxias se apartaban de nuestro planeta a velocidades proporcionales a sus dis. tancias. Más tarde ( 1927 ), los matemáticos desarrollaron una modificación de la ecuación einsteniana, que describía un universo cerrado, expansional, de espacios curvados. 
valores de la realidad -espacic, tiempo, materia, energia-antes tenidos como absolutos, y lo absoluto, el conocimiento humano de los mismos, en donde se ha eliminado la noción clásica de lo infinito. haciendo del universo en que vivimos un orbe finito $y$ sometido por tanto a leyes que es posible investigar por el hombre.

Los conceptos metafísicos fundamentales de espacio y tiempo, materia y movimiento, causa $y$ efecto, han sido por tanto reemplazados por nuevas ideas y sufrido un holocausto en el impacto de la nueva ciencia ( 8 ).

\section{5 - Topografía filosótica de la nueva ciencia alómica}

Una voz se alzó recientemente para acusar a "la implacable ofensiva de la Ciencia" como responsable del caos actual. Mas la Civilización del siglo XX, ccrno una bicicleta en marcha, no puede pararse, pues lo único que la sostiene es su propio movimiento en pos

(8) Albert Einstein, en su articulo "phystics, Philosophy and Scichtific Proyress" (J. Internat. Coll. Surgeons. 14:755-58, Dic. 1950) dice : "Is a matlor of fact, one" casily recognizes certain principal features to which scitnce has firmly adhered ever since those tims:

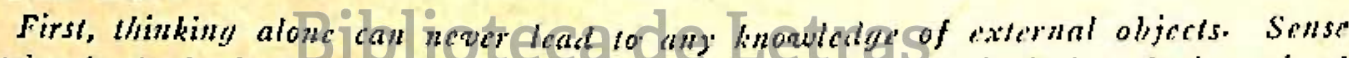
perception is the beginning of all rescaich, and the trulh of theoretical thought is arrived at exclusively by its relation lig the shin lolal of hose Vxpecionces.

Second, all elementary concepts are reducible to space-ime concepts. Only such concepts occur in the "laws of nature"; in this scuse all scicntific thonght is "glometric". A law of nature is cxpected to hold true without exceptions; it is given up as soon as one is convinced that one of its conclusions is incompatible with a single fact achich has been proved by experimental investigation.

Third, the spatio-temporal laws are complete. This means thnt there is not a single law of nature which, in principle, could not be reduced to a lam within the domain of space-time concepts. This principle implies, for instance, the conviction that psychic entities and relations can be reduced in the last analysis to processes of a physical and chemical nature within the nervous systen. According to this principle there are no nonphysical clements in the causal system of the processes of uature; in this sense, there is no room for "free will" within the framcwork of scicntific thought, nor for an escape into what has been called "vitalism".

Just one more renarl in this connction. Even though modern quantum theory contains a weakening of the concept of causality, it does not open a back-door to the advocates of free will, as is already evident from the following consideration; the processes determining the organic phenomena are irreversible in the scuse of thermodynamics and of such a kind as to eliminate the statistical element ascribed to molecular processes". 
de la captura de nuevas fuentes de energía. No obstante, el impacto ha sido terrible. La tradición científica, y con ella las demás tradiciones, han sufrido un treinendo choque. Una vez más, la Ciencia ha chocado con la tradición - que según Freund, representa el super-yo, junto con los ideales del pasado- que desempeña un papel muy importante en la vida humana.

Como resultado de estos años portentosos, el comolejo edificio estructural de la ciencia clásica se ha derrumbado. La ciencia moderna habla un lenguaje totalmente diserente al de antaño. La diferencia práctica entre las teorías newtoniana y einsteniana de la gravitación será mínima, pero la diferencia teórica es tremenda. Al hablar, por ejempla, de espacio-tiempo, en vez de espacio y de tiempo como entidades separadas, estamos simplificando el lenguaje científico, como lo hizo hace muchos siglos en su doctrina un médico llamado Copémico. Al describir el universo como una esfera cuatridimensioñal de diámetro finito, hemos simplificado su concepto. Al referimos a líneas curvas, en vez de rectas, en la teoría de la relatividad, asistimos a un cambio semántico paralelo al científico. Las ideas han cambiado y con ellas el lenguaje.

Si recapitulamas sobre esta gigantesca revolución en el ámbito de la Física y la Matemática, nos apercibimos de que su resultado ha sido desintegrar la vieja concepción, imperante hasta 1900, del universo concebido como un escenario sólido e inmutable de nuestra vida, y convertirlo en un mundoeflúido en dónde no hay nada constante, fijo e inmutable, y en el que las ondas de energía, las leyes de probabilidad, la discontinuidad, el cambio a saltos, la relatividad del espacio y la unidad de éste con el tiempo, han reemplazado las rígidas nociones sobre las que se asentaba el sólido mundo antiguo (9).

En resumen, las características del atonismo físico que han dejado una escara indeleble sobre la faz de nuestro siglo, son las siguientes : a) se ha establecido una nueva ciencia, la física atómica, idea-

(9) A su vez, la astronomía de este medio siglo ha realizado conquistas como el análisis de los movimientos estelares, la confirmación de la teoría de la relatividad, el concepto de las galaxias espirales, la construcción de telescopios gigantes, la radioastronomía, el inacimiento de los paralajes trigonómetricos modernos, la exploración de las estructuras estelares $y$ del polvo y gases interestelares, el auge de la astronomía fotocelular. Como inmediatos objetos de estudio figuran, según Harlow Shapely, la física cósmica, la espectroscopia estelar, estudio de la estructura de la Vía Láctea, dibujo de mapas de las galaxias cercanas, detcrminación del origen del sistema planetario, y el estudio, por las microendas de radio, de los meteoros y de los rayos cósmicos. 
lista en sus concepciones, tan hipotética que uno de sus factores bósicos, el concepto del electrón, es puramente imaginativo; b) frenle a la observación y experimentación como base de la tarea del biólogo, y a las mediciones del físico, la nueva matemática acepta la razón como superior al experimento para llegar a una comprensión integral del universo; c) se acepta la discontinuidad de la materia; d) se ha demostrado la identidad de la materia y energía; e) se ha establecido que el espacio es finito; f) se ha probado la relatividad del tiempo; g) se ha demostrado la continuidad del tiempo y el espacio; h) se ha demostrado que el universo es curvo y cuatridimensional; i) se ha demostrado que la materia se mueve a saltos de energía, y se ha aceptado el salto energético como base de la física moderna; j) se ha reducido el substrato de la vida mental a moléculas y a procesos irreversibles sometidos a un determinismo físico $(10,11)$.

En estos principios puede resumirse la nueva filosofía científica elaborada desde 1900 hasta la fecha, y cuyo impacto psicológico sobre la mente del artista ha determinado las características del arte moderno.

\section{PSICODINAMICA DEL ARTE MODERNO}

\section{6 - Interrelaciones del pensamiento científico y artístico Blblloteca de Letras}

Una de las car̆acterísticas de lä Psicología moderna ha sido ensanchar de tal modo su campo de acción, que le permita aplicarse $a$ mejorar la comprensión de la experiencia y la conducta del ser humano. En los noventa y tantos años transcurridos desde su nacimiento, como

(ro) La física atomística es la física del momento, y ticnde a tratarlo todo de un modo fragmentario, atomístico. Según esta teoría el clectrón pasa de una a otra órbita mediante una seric de saltos, peculiarísimos, porque el electión no pasa de una órbita a otra por el espacio intermediario, sino que desaparece de un sitio para aparecer en otro. E] clectrón no se mueqe a saltos, sino que existe a saltos, se esfuma en un lugar $y$ aparece en otro, sin haberse trasiadiado a ese otro lugar. Por lo. tanto, el electrón es la serie de aspectos separados que ei mismo presentaria en movimiento continuo si existiera tal cosa. Como el universo es materia $y$ ésta se compone de electrones, se ha sugerido que el universo se mueve a saltos entre los cuales desaparece. Acaso análoga toría se podría aplicar a la psique bumana. El salto quántico es ya una realiciad en la psicología moderna.

(ii) Se acepta hoy que los seres vivos están compuestos de elementos biogenćticos de bajo peso atónnico, situados al comienzo de ln escala periódica, teniendo todos ellos - a excepción del zinc, arsénico y yodo- pesos atómicos inferiores al del hierro 
una hijastra de la Filosofía y la Fisiología, el campo de estudio de la Psicologia es hoy lo bastante amplio para incluir problemas tan variadas como el mecanismo neurohumoral de transmisión del impulso nervicso, y los factores determinantes del anhelo humano de comprender el universo (12).

Al igual que la nueva Física, la Psicología moderna es una ciencia de relaciones. Por ello consideramos un abjeto digno de su estudio la interrelación entre la ciencia atómica y el arte moderno, manifestaciones ambas genuinamente representativas del espíritu de nuestro siglo.

En toda época histórica, la verdad científica ha influenciado $-\mathrm{y}$ a la inversa- al pensamiento artístico. El artista no refleja necesariamente en su arte de un modo deliberado la verdad científica, mas si el clima de una época está saturado de nuevas ideas, el artista, como barómetro el más sensible existente, las refleja en su obra. Recordemos la palabra sabia de Zola. "L'Art c'est la Nature vue par un temperament". Ese temperamento del artista está sometida al influjo de cuanto sucede en el horizonte de su tiempo. Evocar la revolución científica de nuestro siglo y su impacto psicológico sobre el artista, equivale

(56). En el otro extremo de la cscala periódica, hallamos los elementes de mayor peso atómico, entre los que figuran tcomenzando por el plomo (207), cl radón (222), cl radio (226), el actinio $(227)$ y el uranio $(238)$, elementos que, junto con sus isotopos, son todos radioactivos, ousgecir, látomosefácilmente vesintegrables, y cuya fisión se desarrolla con llibenación de energia.

Los átomos más inestables se hallan en ambos extremos de la cscala periódica, siendo la plata el único elemento de perfecta estabilidad, y estando cerca del punto medio de la escala ( 108 ). Los otros elementos son metastables en una u otra dirección, y liberan energía por la conversión de sus átomos, ya sea al adicionarse sus componentes nucleares en los elementos más ligeros, o al desintegrarse el núcleo en los más pesados.

L.os elcmentos biogenéticos tienen en cambio una mayor cstabilidad nuclear. Seaborg compiló en roft una lista de los isotopos canocidos hasta entonces, de los que 45 eran radioactivos. Trazando la frecuencia de la radioactividad en los isotopos y en los átomos normales, en grupos sucesivos dentro de las series periódicas, y considenando la proporción de cuerpos radioactivos en cada grupo, vemos qua la curva se superpone a la de la cstabilidad del núclco atómico. Gamow dijo, en $19+6$ : "la mejor oportunidad de producir trasformaciones atómicas y liberar su energía oculta radica en ambos extremos del sistema periódico : el isotopo pesado del hidrógeno deuterium o el isotopo ligero del uranio ( $U_{235}$ ), ambos, elementos muy raros en el planeta".

(12) Los cambios en la Física han conducido a cambios similares en la Biología. La Mídiciran está hoy más interesada en cambios químico-energéticos intraorgánicos que en alteraciones neurológicas más groseras. La unidad de la materia y la 
a apuntar hechos que habían pasado inadvertides, puede dar nueva significación a las tendencias ideológicas, e influenciar así el curso de la actividad futura del artista.

Al intentar establecer el impacto del atomismo científico sobre el arte moderno, estamos intentando hacer historia viva, anticipar en cierto modo lo que los historiadores del futuro interpretarán dentro de unos años, cuando sea más serena su perspectiva de nuestro tiempo.

Recordemos como ejemplo de lo dicho, que así como la Física y Matemática de los siglos XVII y XVIII ayudaron a descubrir la circulación de la sangre y la físico química respiratoria, así el progreso científico del siglo XIX tuvo amplias repercusiones culturales.

En 1865, Claudio Bernard en su "Introducción al estudio experimental de la Medicina" formuló los principios de la nueva ciencia médica, considerada como ciencia positiva basada en la razón y en el método experimental. Sus conferencias y experimentos en el Colegio de Francia, tenían como espectadores a fisiólogos, químicos como Berthelet, filósofos como Janet, e historiadores como Renán. Fin la misma época, las conferencias clínicas de Trousseau, y, más tarcle, las de Charcct en la Salpetriére, tenían entre el público a escritores, filósofos, historiadores y artistas.

Las repercusiones fueron desconcertantes. Renán aseveró que la. Historia era una ciencia como la Química. Taine afirmó que el vicic. y la virtud eran productos quimicos como el tvitriblo y el azúcar, inspirándose para su teoría del deterministo ambientalista individual en Augusto Comte y Claudio Bernard. Víctor Hugo declaró en 1859 que la

energia no se acepta sólo para el universo, sino para el cuerpo humano.

Se ha comparado la energia originalmente desarrolladia, en el zigote, que provec el ímpetu que proyecta al organismo como una bala en su paso por la vida, a una explasión de energia atómica. En el momento del nacimiento, sólo resta el $2 \%$ del impetu inicial, que va decayendo constantemente desie su descarga, por cstat sometido a las leyes termodinámicas aunque la función de la vida mantience esa energiá que se disipa a un nivel ítil (W. Langdon Brows).

Los tejiclos argánicos y nerviosos, como agregatos moleculares gue son, resisten los cambios de las moléculas individuales de su medio ambiente, pero están sometidos a las leyes estadísticas de la física.

La fisica moderna acepta el cuerpo humano como un continuo de materia $y$ energía, como clectrones cargados de energia, cuyo contenido encrgético no varía continunmente sino a saltos, según la teoria de los quanta, y moviéndose, seggún Schrodinger, en un continuo de espacio-tiempo de cuatro dimensiones. Ciłda sistema orgánico ticne una cantidad de cnergia cuyo nivel cambia por ese misterioso acontecimiento que se llama un salto de quantum. Cada molécula de dicho sistema está formada de átomos y tiene 
misión del pceta y filósofo, era intentar manejar los hechos sociales como el naturalista los hechos zoológicas. Flaubert afirmó que la novela debía ser científica. De esta influencia nacieron novelas que eran verdaderas historias clínicas, como algunas de los hermanos Goncourt, y las de Emilio Zala. De Freud y del psicoanálisis nació más tarde la novela de tipo psicológico, que aun es la más leída en nuestro tiempo.

\section{7 - El artista y su época}

Para el artista, como para cualquier otro hombre de cada generación, vivir es realizar una faena bidimensional, consistente en recibir lo vividc $\mathrm{y}$ en dejar fluír su propia espontaneidad. El artista, antes de serlo es un hombre sometido a una doble serie de estímulos biológicos, provenientes unos del medio externo y los otros de su propia individualidad.

Ortega y Gasset ha hablado de la doble dimensión del hombre que es su dimensión histórica -rasgo hereditario-, y su ambición de futuro. Historia y destino. Ambas factores son los determinantes de esa ecuación de vida, cuyo desarrollo puede ser a veces tan elegante como la demostración de un teorema matemático.

El artista, comoihombre que es antes de ser profesional, determina a través de los órganos de los sentidos su ordenación orgánica, y su ser es él y su circunstancia, como ha demostrado von Uexkull.

cierta estabilidad, no variando su configuración hasta que recibe de afuera la energia necesaria para el citado salto. Dicha diferencia de nivel detcrmina cuantitativamente cl grado de estabilidad de una molécula.

Estas condiciones, existen en el ser humano desde antes del nacimiento. La física moderna considera la posibilidad de que un gene o una fibra de cromosoma sea un sóliclo aperiódico. Esta concepción de una asociación bien ordenada de átomos con suficier te resistencia para conservar su orden permanentemente, $y$ hacer arreglos isoméricos, puede acaso explicar el enigma de cómo la partícula diminuta del núcleo del huevo fertilizado contiene escrito como en minúscula clave todo el desarrollo futuro del organismo.

Tras el nacimiento, la vida sigue como un incesante cambio bioquímico, aunque manteniendo su unidad, integración y organización interna, contra los embates del medio externo.

Interesa anotar que se han abolido las diferencias fundamentales entre los organismos vivos y no vivos. Los virus pequeños son considerados por los químicos como moléculas $y$ por los biólogos como células, a las que acaso pueda aplicarse la teoría de los quanta. 
El artista moderno cuya obra se ha desarrollado en el último medio siglo, ha estado sometido al clima histórico de nuestro tiempo, cuya influencia más notable ha sido la revolución científica. En épocas pasadas el artista traducía las ideas de la clase gobemante, usando como cañamazo para expresarlas, paisajes, figuras y ambientes de su tiempo. En la época atómica, que se inicia con los comienzos de este siglo, el artista ha estado gobernado por la fuerza de las nuevas ideas que forman el organismo ideológico del nuevo siglo.

Más artesano que bohemio, el artista actual es a la vez un hombre de negocios en sus transacciones, y un hombre de ciencia en sus métodos. Esa es la diferencia radical entre el nuevo artista, que todo lo fía al estudio profundo de su tema y pone su técnica al servicio de una idea, y el artista clásico en quien eran supremas la inspiración y la improvisación.

No olvidemos que cada pincelada, cada brochazo, tienen detrás una mano y un brazo movidos por un hombre, cuyo cerebro está siendo permeado continuamente por el clima de ideas del siglo en que vive el artista. Para él tiene gran importancia el vivir en un siglo teñido de política o en un siglo coloredda de guerras. El nuestro ha sido un siglo de tremendos avances científicos al servicio de fabulosas creaciones tecnológicas y de apocalípticas orgías de destrucción.

El cerebro del artista, como un pequeño cosmos, ha estado iluminado por el sol de lds nuevas ideas, $\mathrm{y}$ su mano ha estado influenciada por las nuevas técnicas deb hombre de cienciaisque subconscientemente mueven las manos del artista en su turbulento taller, como guían las del técnico en la paz iluminada de su laboratorio.

\section{8 - Perfil psico-histórico del arte moderno}

En la primera parte de esta disertación seleccionamos la fecha de 1900 - el año en que Planck formuló su teoría de los quanta- como marcando el comienzo de la nueva ciencia atómica (13).

(13) La vida humana, se ha dicho, es la captura de "nivcles de energía". Hasta el año 5000 antes de Cristo, el hombre sc limitó a capturar la encrgía solar, rccogiendo animales y plantas comestibles, desarrollando al mismo tiempo pobres culturas. Hace unos 7000 años apareció el hombre agricultor, que llenó los campos de plantas comestibles, aprisionando asi más energía, método que en rooo años creó vastas civilizaciones; durando esta etapa unos 6000 años. En 1700, en la Europa occidental, sc usaron los "combustibles fosilizados" o scan carboncs, petróleos y gas.

Una nueva cultura se desarrolló al explotar la primera bomba atómica en Alamo Gordo, Nuevo México, el 16 de julio de 1945 , seis años después de descubrir Otto Halm 
Pademos elegir la fecha de 1907, en que con "Les Demoiselles d'Avignon" lanza Picasso al mundo su manifiesto pictórico cubista, como el año que inicia el arte abstracto no-objetivo, cuyas relaciones con la ciencia atómica forma la segunda parte de este estudio.

Pasemas revista brevemente al desarrollo histórico del arte moderno, a sus características generales, y al impacto psicológico de la ciencia atómica sobre el arte abstracto de nuestro tiempo.

Antes del siglo XVIII, durante 2000 años, el artista dependía casi exclusivamente del patronaje de las Iglesia y de la Corte real. A partir de la Revolución Francesa, es el negociante quien le protege, encargándole cuadras y retratos de apacibles temas burgueses. Ello obligó al artista a elegir temas "que se entendieran". Los artistas rebeldes como Courbet, Manet, Pissarro y Seurat, quedaron aislados, y su protesta les llevó a usar un método semicientífico, objetivo, de registrar la luz, que consistió en el empleo de colores puros, que se fundían en el ojo del espectador y no en la paleta del pintor, abstrayendo con ello la forma de las cosas. La luz que tánto cautivaba a los impresionistas minó subconscientemente en ellas el interés hacia la forma de las cosas y hacia el paisaje como tema pictórico.

Como reacción, y para restaurar la estructura arquitectural del tema, Cezanne usó más tarde la geometría, haciendo del cilindro, el cono y la esfera, la esencia de todas las cosas, y Seurat empleó líneas verticales, diagonales y horizontoles, comomodo de lograr la desnaturalización de personas y objetos. Con ello, ambos artistas limitaron y desnaturalizaron "la Naturaleza, haciendo de ella un continuum de espacio-tiempo, como los físicos y matemáticos lo harían más tarde en las ciencias exactas.

Cezanne igualó el valor como temas de las naturalezas muertas y los sujetos humanos. Al correr de los años, los rebeldes intelectuales proyectarian en el siglo XX su impulso rebelde de analizar en el arte abstracto las formas prácticas halladas en la Naturaleza muerta, y los rebeldes no racionalistas destacarían el espacio dinámico de los paisajes en sus composiciones surrealista. Tales fueron las téndencias psicológicas determinantes de las dos grandes directrices del arte moderno.

y Starassmann la fisión de núcleos pesados del uranio. Este acontecimiento científico que tuvo aplicaciones prácticas inmediatas a la manufactura de "rastreadores" radioactivos, la curación del cáncer, prolongación de la vida, y conversión del hidnógeno en helio, permitirí capturar aún más energía. Se ha calculado que una libra de materia desintegrada en energía daría una fuerza comparable a la derivada de 4 billones de libras de carbón. 
La pintura cubista nació a comienzos del siglo actual bajc. la tutela de Braque y Picasso, del culto de lo exótico, del ballet, del estudio de las máscaras africanas, del interés por el folklore negro y el primitivismo, de un deseo de fuga - porque Arte es evasión-, y de la sed de saber agudizada por la ciencia nueva.

El abjetivo del cubismo no fué lograr el placer visual, sino hacer del arte un instrumento científico-filosófico de investigación, siendo la suya una rebelión, análoga a la científica, contra el clasicismo, y destacando nuevos conceptos en la realidad del mundo visible. Dudando de los sentidos ccmo vehículos del saber, recayeron en la mente lógica y plástica, rechazando los conceptos arquitecturales y esquemáticos del orden clásico.

El arte cubista es incoherente porque adopta libertades musicales y utiliza combinaciones nuevas de formas concicidas, para lo cual rompe los objetos, recomponiéndolos luego en una estructura nueva. $\mathrm{Su}$ objeto es el desarrollc orgánico de formas puras no simbólicas en un espacio imaginativo bidimensional, $\mathrm{con}$ el objeto de pintar no temas sino cuadros.

Los planos del cubismo son las de una vista sintética, que va hacia el observador y no se retrae en un espacio ilusionístico como sucede en los cuadros clásicos. El marco del cuadrc no es una ventana que da a la lejanía, sino un límite de espacio. El cuadro es monocromático y bidimensional lipara acercarse máslad espectador. Es un arte de naturaleza muerta, interrelaciones estáticas, enclaustramiento e
inmovilidad.

El cubisma representa la etapa final del ciclo iniciaclo en el Quatrocento, con la pintura clásica, que era una pintura "de bulto" o "de hueco", de objetos, en la que el pintor trataba de representar las cosas objetivamente. La etapa siguiente fué la de los impresionistas, que ya no pintaban cosas, sino sensaciones; pintura subjetiva a la que interesaba pintar no lo visto, sino el propio acto de ver. El Cubismo como acto final, -ya no se interesó en cosas ni en sensaciones, sino en ideas. Renunció a ser un arte objetivo como el clásico o subjetivo como el impresionista, para ser proyectiva. De espaldas al mundo, el pintor dejaba de hacer que sus retinas fueran esponjas empapándose de la forma y color ambientes, para cerrar los ojos y proyectar sus ideas.

Esta evolución del arte ha sido paralela a la de la Física, que de la investigación de las cosas por la observación naturalista pasó a estudiar las percepciones de las cosas, para terminar analizando el es. 
quema ideológico de las mismas. En este tránsito de la realidad externa a lo subjetivo, y lo intrasubjetivo, o sea en el desplazamiento del punto de vista ante el universo del investigador científicc y del artista, radica la clave interpretativa de la evolución del método científico y de la técnica artística.

El futurismo, que nace en 1910, se interesa en el paisaje como el cubismo en las naturalezas muertas. Es el arte que glorifica el dinamismo de la máquina, y nace en el Norte de Italia, en los años en las que había tenido lugar allá una gigantesca explosión de poderío industrial. El maquinismo industrial y el fascismo incipiente, con el culto a la fuerza, el dinamismo, la velocidad, "la vida peligrosa" y la fuerza, incubaron el futurismo. Fué un arte de movimienta y fuerza, de personas y animales en movimiento, calles vertiginosas, máquinas en acción, fábricas y ciudades que sorbían en su torbellino al espectador. No fué arte de gabinete como el cubismo, sino de plaza pública e interrelaciones dinćmicas.

A continuación sobrevino el advenimientc del surrealismo, con Dali, Ernst, de Chirico, Klee y Tanguy. Arte fantástico, incluyó obras caracterizadas por su deliberada incongruencia, su constante inconstancia, teniendo como objeto principal sorprender al espectador con la inesperado, violando el convencionalismo y la costumbre, creando sus propias leyes en un mundo sin ley. Su truco técnico fué pintar con gran realismo cada frágmento de lo irreal, del universo de fantasmagoría y pesadilla, en donde el esmero con que se pintaban los componentes del sueño hacian aceptar su irrealidad como posible.

Sus temas eran sueños extraordinarios fabricados con cosas ordinarias y familiares, con dobles imágenes, cada una de las cuales representaba algo por completo diferente, con la ilógica ilación de los sueños. Fué un arte que exaltó la libertad espacial, subconsciente. Fué un arte visceral, profundo, cavernoso, disecante, que se interesó por la figura humana y por el paisaje. Remotamente vinculado con la compulsión expresicnista, buscó el espacio dinámico y las formas orgánicas de paisaje (14).

\section{9 - Boceto y dinámica del arte abstracto}

La etapa siguiente fué el nacimiento del arte propiamente abstracto, que en realidad se origina muchos siglos antes de nuestra épo-

(I4) El extraño juego de "aparece y csconde" presente en tantos cuadros surrealistas, por ejemplo, en Dali y Tchelitchev, come imágenes de seres multiplicados al 
ca, cuando los artistas flamencos del siglo XV y XVI comenzaron a abstraer, o sea, a eliminar los elementos superfluos de sus cuadros dejando sólo los factores básicos.

En nuestro tiempo esa tendencia se desarrolló al máximo en el arte abstracto, que tuvo como factores determinantes el progreso de las artes fotográficas que convencieron al pintor de que la cámara fotográfica podía, en muchos casos, conseguir resultados objetivamente superiores a los logrados mediante el pincel; la influencia de la música que inspiró al artista el anhelo de crear un arte universal, una lengua internacional emocional que se liberase en el espacio, como la música lo había logrado en el tiempo, del provincianismo de los temas locales; los descubrimientos científicos, en especial del microscopio de alta potencia y los telescopios de largo alcance que han ensanchado el hcrizonte visual del hombre, y el desarrollo de las cámaras estraboscópicas que permiten registrar el movimiento más veloz.

Todos estos factores unidos al avance del maquinismo, introduciendo formas cilíndricas, cónicas y esféricas, que han ido reemplazando las formas halladas en la Naturaleza, e influenciando al artista que paulatinamente fué abandonando el universo que veía con los ojos de antaño, en favor del universo que a fragmentos y jirones se va descubriendo y ampliando a diario. El orden tradicional de espacio, forma y color ha sufrido una revolución paralela a la científica, en la que además seb hointroducide el fáctor del tiempo y el movimiento.

Tanto en sus formas más intelectuales y geométricas como en las más emocionales y románticas, el arte abstracto se ha caracterizado por adoptar varias directrices que pueden resumirse del modo siguiente : a) Preferencia por temas basados en formas mecánicas o arquitectónicas, naturalezas muertas y objetos inanimados, favoreciendo la representación de lo mecánico, lo mineral, lo telúrico o lunar, lo maquinístico. Raramente aparece la figura animal o humana en el arte abstracto -excepto en el arte surrealista-, que parece estar vuelto de espaldas al mundo exterior objetivo. b) Adopción de un espacio bidimensional limitadc; que es un fin en sí mismo; un espacio finito como el universo einsteniano. c) Introducción del color como elemento dinámico de la propia forma; introducción del tiempo y el mcrimiento en un arte, hasta nuestro siglo, eminentemente estático. El arte abs-

infinito, es una represcntación alegórica de la auto-imagen psicológica rota lambién por el impacto psicoanalítico. Es la mente que se está buscando a sí misma. 
tracto -como la nueva Física- gusta de animar lo estático e inanimado $\mathrm{y}$, a veces, de inmovilizar lo humano y animado, como en una tentativa de unificación atomística de lo vivo y lo no viviente. d) Adopción, casi mística, de un propósito de unidad en sus fines. Contrasta en el arte abstracto - como en la nueva Física- la rigurosa austeridad de los métodas, de un objetivismo científico, con lo místico de la intención de llegar a comprender -y ordenar- el universo (15).

El arte abstracto puede clasificarse según su principal objetivo, - sea : la representación de formas geométricas abstractas, representaciones geométricas estilizadas, formas orgánicas abstractas o farmas orgánicas estilizadas.

En el primer grupo podemos incluir los cuadros sin tema determinado que no representan sino una forma geométrica pura y abstracta, interseccicnes de líneas $Y$ ángulos rectos, serie de formas geométricas de cuya simetría recibe el espectador una impresión agradable y armónica, como la dan ciertas fugas de Bach, el matemático de la música. Es un arte que evita la curva y se recrea en la línea y el ángulo rectos, emplea grandes rectángulos lisos de intensidad uniforme y sin sombreados, separados y unidos a la vez por bandas más estrechas. Arte puro, abstracto, ascético, de inmaculadas blancuras y gran precisión matemática. Su figura suprema fué Mondrión, el pintor holandés, creador de un espacio abstracto de colores primarios, y de una forma rítmica pura, casi musical, que seleccionó bos colores que correspcnden ópticamente ja la formai espacial deseada. Sus principales apóstoles han sido Van Doesburg, Gabo y Nicholson, siendo un arte simbólico de nuestra era de alta ingeniería obsesionada por el orden matemático y la mecanización del universo.

Cuando al estilo antes descrito se agrega la representación de un objeto, se crea el arte de representación geométrica estilizada. Su objetivo es representar objetos gecmétricc:s, despojándolos de todo lo supérfluo y dejándolos reducidos a su forma esquemática, a su esqueleto, al símbolo puro de la cosa. Las líneas verticales y horizontales se usan para representar objetos a veces macizos y compactos. No sólo lo inanimado, sino lo vivo puede representarse geométricamente

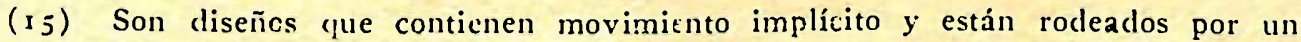
espacio indeterminado. Se han usado en carteles, anuncios, mucbles, arquitectura y cerámica. Por parecer cortados de un diseño grande llama la atención su existencia orgánica $y$ libre. Es un estilo usado en las hamacas de lona mociernas, en sillería, muebles y escaparat:s, con enorme éxito. 
en este grupo, pero en formas mecánicas destinadas a acentuar la estructura básica de una cosa. Un jarro o un ánfora se representan como el jarro o la botella, que simbolizan tocios los jarros y ánforas del mundo. No son cosas, sino el telegrama de las cosas, su taquigrafía geométrica. En vez de líneas y planos rectos construye volúmenes de tres dimensiones, sobre todo cilindros, conos y esferas, que según Cezanne, eran los elementos básicos de la Naturaleza. La luz es siempre teatral en estos cuadros, y los objetos aparecen en drámatico aislamiento - agrupados en forma de un ramillete de símbolos. Fernando Leger ha sido el astro sol de este estilo, y Archipenko y Le Corbusier sus satélites.

A veces el arte abstracto puede utilizar formas que inconfundiblemente representen o sean sugestivas de la vida y de lo vivo. Es el arte hecho famoso por el ruso Jean Arp, por Calder, Noguchi, y Joan Miró (uno de los más originales y encantadores pintores de nuestro tiempo). Para definir las obras de Jean Arp, no se podría usar mejor imagen que decir que son como si una escultura representando un torso humano cayera en una playa y fuera abandonada a la intemperie, batida por el oleaje y azotada por el viento durante horas, días, mes y años, hasta quedar todas sus aristas borradas, sus planos suavizados, sus contornas difuminados, sus esquinas $\mathrm{y}$ ángulos borrados. Restaría así lo que pudiéramos considerar como el espíritu de la forma primitiva, lo que hay en un torso humario bajo sus ángulos y sus icurvas, sus pliegues y sus caristas.in Alr phanacorfado el trabajo de la Naturaleza y procedido a saltos, lo que concuerda con las leyes de Planck y las teorías de Uexkull. Este arte incluye figuras pintadas o esculpidas irregularmente, de contorno flúido que evita tanto la curva geométrica regular coma la línea recta, curvas ninguna de cuyas partes se parece a la otra, que no están trazadas repitiendo una unidad básica, sino que crecen según un ritmo de desarrollo cambiante. La forma resultante no puede romperse en partes y debe considerarse como un todo único. Cada unidad de estas formas libres no debe descomponerse en partes sino aprehenderse como un todo, estando unida en sus partes por una superficie o tensión de contorno como la de las células de los seres vivos. Su principio de unificación es interno, y cada forma integrante contiene la posibildad de cambio sin perder su identidad.

A veces la forma orgánica se aplica a la imagen, y no para incluir los objetos en un orden y ritmo medibles como hacía la forma gecmétrica, sino para darle a las cosas la fluídez de la forma. En vez 
de una estructura esquelética, este tipo de forma orgánica estilizada prefiere formas bulbosas y protuberantes de contornos suaves y estilizados, que indican que las más complejas formas de vida que conocemos derivan de simples crganismos celulares y siguen pareciéndoseles. Son formas simbólicas semejantes a las especies naturales de las que evolucionaron, pero con sus propias leyes de desarrollo. Son, por ejemplo, partes del ser humano, mancs o pies, aislados y vivos, comentarios trágicos o humorísticos sobre el ser humano al que aún se le parecen. Miró, Henry Moore, Picasso y Paul Klee, son los profetas de este estilc que a veces es una línea vagabunda, con figuras creadas al parecer de una línea sin propósito, que incluye una forma abstracta, pero encerrando una representación indecisa y cabalística, cuyas posibilidades han sido explotadas por la caricatura moderna.

\section{0 - Un comentario sobre el sentido de la forma en el arte moderno}

Acaso en donde más se aprecia el cambio revolucionario que el arte abstracto representa en comparación con el arte clásico, es en su ccncepto de la forma humana, lo que merece un comentario especial.

La anatomía artística ha reflejado sucesivamente en su iconografía el clima imperante en cada época histórica, tal como la visión alegórico-religiosa medioeval, el modo arquitectónico renacentista, el movimiento mecánica del Obarroco Coel evolucionismo del pasado siglo (16). Laín Entralge tha desmotradon excelentemente esta correlación.

En nuestro tiempo, el cambio en la morfología humana que se aprecia en el arte abstracto ha sido paralela al cambio acaecido en las concepciones de la anatomía científica. En los últimos veinte años se han alzado muchas voces proclamando que la Morfología como ciencia estaba en crisis de anquilosamiento y que debía revivirse la actual anatomía del cadáver haciéndola síntesis fecunda en vez de análisis estéril. La Anatomía debe aproximarse a la Fisiología, se ha repetido insistentemente por biólogos y anatómicos, renunciar al estudio de particularidades, y ser dinámica en vez de estática. Ese anhelo de dinamismo en el estudio de la forma, ha palpitado tanto en las salas de disección ccrmo en los talleres de los artistas.

(16) Significativo es que la nomenclatura anatómica comenzara en la Historia siendo numeral y expresando magnitud (duodeno = doce dedos), para trocarse en el Renacimiento en símbolos de ordenación $y$ relación (deltoides $=$ delta), como ha demosirodo Lain Engralgo. 
El ser viviente había sido considerado por la anatomía de antaño en su proyección en el espacio, reservando para la Fisiología su estudio en su proyección en el tiempo (17).

El anatómico del siglo pasado - como el artista- estudiaba al ser humano como un todo cerrado en sí mismo. El enfoque era por tanto de causalidad, estudiando el ser vivo como figura geométrica, como algo ya dado, en el sentido platónico. Era una concepción mecanicista, estática, que se traducía en el arte en la realización estética pura de una idea estilística. Los seres humanos se concebían como en la Ontología platónica, modelando la materia a imitación del arquetipo eterno de las ideas.

La nueva Anatomía ha concebido al ser vivo ccmo puro proceso, del que interesa tanto su aparición como su devenir y los fines de sus cambios biológicos. Es un concepto aritmético, finalista, que enfoca al ser vivo como proceso fisiológico, siendo una noción teleológica al modo aristotélico, entendiendo a todo ser como compuesto de materia que es la potencia, y forma que es el acto o entelequia. Esta concepción se ha traducido en el arte en el estudio de la forma humana sometida a una conformidad a plan y con una tendencia dinámica hacia un fin, como sucede en el arte moderno. A la forma como idea del arte clásico, se opone en el arte moderno la forma ccmo función o como finalidad en sí misma.

El arte abstracto Lcomo la nueva Ânatomía- acepta que la forma puede ser finălidad,pbaseidella lanción $\theta$, función misma, que existe antes de la estructura. La forma no se concibe como simple manifestación del ser vivo en el espacio, sino sobre todo como función proyectada en el tiempo. La nueva morfología artística es sobre todo fisiología. El artista moderno cree que ya no puede hacerse geometría pura espacial liberada del tiempo, ni tampoco fisiología temporal pura liberada del espacia, por lo que ha incorporado a su arte, forma y función como manifestaciones supremas del ser viviente, ,como la materia y la energía lo son de lo inanimado.

En el terreno práctico esto ha significado, una revolución en el arte de ver los seres vivos. Los huesos, los músculos, las demás estructuras anatómicas siguen estando donde siempre, mas nuestra posición para mirarlos ya no es la de antes. No ha cambiado el sujeto

(17) Análoga división podría aplicarse históricamente, habicndo sido el estudio del ser humano en su proyección espacial objeto de la Geografía, como en su proyección dinámica ha sido el sujeto de la Historia. 
de observación pero sí la óptica empleada. La forma humana ya no es para el artista abstracto mera expresión del ser viviente, configuración material en el espacio, representación alegórica del ser vivo, o resultado de un esquema espacial, sino puro proceso dinámico, movimiento en el tiempo. Por eso el arte abstracto ha renunciado al estatismo del arte clásico que no le permitía captar las realidades funcicnales de la forma, y se ha hecho eminentemente dinámico, en perenne caza de la forma como función, en el tiempo y el espacio.

\section{EL IMPACTO PSICOLOGICO DE LA CIENCIA ATOMICA SOBRE EL ARTE MODERNO}

11 - El proceso psicobiológico de la formación del "esquema espacial" del medio externo

¿Cuáles han sido las consecuencias del impacto psicológico sobre el hombre moderno de esta nuova scienza atomística? Podemos sintetizarlas afirmando que el resultado de las concepciones antes resumidas de Física moderna, ha sido destrozar por completo lo que podemos llamar esquema espacial psicológico que del universo tenía el hombre.

El ser humano vive en un medio ambiente del que recibe continuamente a través de las ventanas de los sentidos, impresiones que labran en el sistema nervioso huellas o engramas que llegan finalmente a formar parte de nuestro organismoul Eil conjunto ndelas huellas creadas por las varias excitaciones engráficas, forman el llamado correlativo interno del medio externo, y crean en la mente humana el esquema espacial del mundo exterior.

Como la forma de los engramas varía según sea la estructura interna de cada organismo, hemos de aceptar con Uexkull, que cada animal tiene su mundo especial interior en el que existe una arquitectura engráfica específica de la que depende su mundo extemo. Es decir, que el mundo externo de la medusa difiere del mundo externo del hombre, y èl de éste mundo del tejón o de la mariposa, porque cada especie recibe distintas excitaciones engráficas, visuales, olfativas, tactiles, auditivas, térmicas o de presión, que graban una imagen interna o esquema espacial diferente del mundo externo, variable en cada individuo. De ahí que la denominación de "mundo externo" sea un término variable desde el punto de vista de la especie considerada.

Los citados engramas y los estímulos externos que los originan, condicionan en cada instante la actividad del ser vivo, incluyendo su 
conducta estética. El ser humano forma por tanto su universo a imagen y semejanza de los engramas que de él posee. La imagen humana del universo varía según las imágenes sensoriales y mentales que del universo se forma el hombre, gracias a sus lecturas y meditaciones. Aunque los estímulos externos sean iguales, el organismo reacciona a ellcs diferentemente en cada instante. Su reacción está, pues, condicionada - al modo pavloviano- por estímulos externos o sensoriales, e internos o biopsíquicos.

Durante miles de años, el ser humano vivió con un esquema espacial en su mente del que resultaba la imagen de un universo de perfecta geometría, situado en un espacio infinito, en doncle la materia lo era todo, siendo inmutable y respondiendo a leyes más inmutables todavía. Cuando en estos últimos cincuenta años la física atómica destrozó la concepción de ese universo, desintegrándolo en átomos, alteró su perfecta geometría convirtiéndola en un caos de probabilidades, reemplazó la perfecta continuidad de antaño por la discontinuidad física, estableció el cambio a saltos en vez de la evolución continuada, y deshizo por completo el esquema espacial del hombre en que se basaba su imagen del universo. En vez de su antigua imagen espacial firme, segura, definida, sólida y continua, el hombre se halló con la imagen de un orbe finito en el que todo era alteración, improbabilidad, desorden, discontinuidad y salto.

\section{2 - La destrucción de ga imagen corporal del hrombre}

Las consecuencias de la nueva Biología y Psicología fueron análogamente cataclísmicas para los esquemas espaciales y corparales del ser humano. La nueva Biología de von Uexkull demostró que era preciso acabar con el darwinismo $y$, en su lugar, establecer que el proceso de la vida era el de seres cuya estructura se basaba en una conformidad a plan, y que progresaban a saltos biológicos, no muy diferentes de los saltos físicos de Planck. El salto reemplazó totalmente a la evolución continuada en la concepción del progreso biológico.

La nueva Histología, con el refuerzo de los microscopios de alta potencia y finalmente del microscopio electrónico, revolucionó también el concepto del cuerpo humano, que en psicología moderna se llama imagen corporal, o sea, el esquema morfológico que de sí mismo y de sus semejontes tiene cada ser humano (18).

(18) Cuando esta imagen desaparece o se deforma por lesiones neurológicas, puede liberarse del marco corporal y convertirse en la alucinación que ha daclo origen 
Hasta comienzos de siglo la anatomía era estática, solidificada, fija, rígida, y el ser humano estaba formado como un pequeño microcosmo de piezas tan sólidas y sometidas a leyes, pesas y medidas, como el macrocosmo en derredor suyo lo estaba a las leyes de la Física. La nueva Histología ultramicroscópica, desintegrando en elementos hasta hoy invisibles al ser humano, y las nuevas concepciones fisiológicas y dinćmicas de la antes estática anatomía humana, dieron como resultado que la imagen corporal del ser humano quedara también destrozada, deshecha, transformada la ordenada concepción de antaño del organismo humano en una confusa imagen de elementos moleculares en perenne agitación y desconcierto (19).

La nueva Psicología psicoanalítica de Freud contribuyó a esta revolución, al establecer la supremacía de la vida no racional sobre la vida racional, y al crear una psicología abisal que daba más importancia a las partes profundas, instintivas, no racionales del espíritu que a la vida consciente. Un mundo de las tinieblas, todo violencia, lujuria y destrucción, reemplazó al mundo de orden y moral creado laboricsamente ccmo superestructura psíquica por la cultura y la religión. La tercera gran imagen o esquema del ser humano, que era la del orden, fijeza y ley de su vida mental, quedó también sustituída por el nuevo esquema freudiano de la vida psíquica, en donde la parte profunda de la mente era el factor decisivo.

\section{3 - El impacto psicológico de la ciencia tatómica sobre el arte} moderno

El hombre de nuestro siglo reaccionó a esta destrucción cataclísmica de los valores básicos de su vida, del esquema espacial del universo de su imagen corporal y de su auto-imagen psicológica, con una vaga, a veces violenta, reacción de desconcierto. Mas el artista, que

en la literatura a la leyenda del "doble" humano, cuya visión anuncia la muerte, y que no es sino la percepción sin objeto de nuestra propia imagen corporal.

(19) En los días felices del arte pagano, el esqueleto era invisible en la pintura. En la Edad Media, caballeros, damas, obispos y pajes exhiben la carne sin asomar en los cuadros los cráneos ni los huesos. Aldous Huxley se preguntaba una vez, y no sabía qué contestar, a qué obedecía esta tardía aparición del esquelto en el arte. La respuesta a mi entender es la aparición en $15+3$ de la primera obra que representa un esquema espacial de la anatomía y el principio de la Ciencia moderna, que es la "Fábrica" de Vesalio, en donde la magia de las ilustraciones de Calcar, bajo la dirección del belga genial $y$ rebelde, introduce en el arte el hueso $y$ el esquelto como suprema expresión 
es siempre el más fino barómetro espiritual de una época, reaccionaría de un mado más radical, reflejando en sus técnicas su desconcierto ante esta ruptura de los esquemas vitales, y tratando de rebelarse $\mathrm{y}$, en cierto modo, de resolver el cataclismo que amenazaba a los valores hasta entonces considerados como inmanentes del ser humano.

El objetc del artista es reproducir la belleza del mundo exterior. Mas la belleza no es -como ya Kant estableció- un predicado de las cosas dotado de realiaad objetiva, ya que el canon estético varía de un país a otro y de una a otra época - la belleza para un zulú es muy diferente que para un esquimal, y para un pintor del tiempo de Greco muy distinta que para un surrealista actual. Por ello, al variar la actitud científica ante el objeto exterior -el universo- y cambiar los esquemas espaciales y corporales del sujeto, se determinó una tremenda variación en el canon estético de nuestro siglo (20).

El pintor - a quien hemc:s adoptado como ejemplo el mús patente de nuestra tesis- hoy, como hace dos mil años, usa uno de los dos grandes -sentidos estéticos, o sea, la vista, para percibir los estímulos plásticos externos de tipo estático en los que se basan las artes espaciales o visivas (pintura y escultura), como las artes temporales $\circ$ auditivas (música) se basan en el uso del oído para captar los estímulos rítmicos y melódicos.

de la forma humana. A continuación de esta obra, ya la forma de los dormidos se va esculpiendo $t \mathrm{n}$ los sepulcros. En el siglo XVII estas efigics'se alzan y abren los ojos. Al pie de las figuras hay cráneos dibujados, acaso en recuerdo de las pandemias luéticás que al dejar a sus víctimas sin nariz les hacían acordarse de la existencia de su esqueleto. Al correr de los años el esqueleto crece, $y$ cobra alas en las esculturas de los panteones.

(20) De vital importancia para comprender el impacto del atomismo sobre el arte moderno, es entender que la percepción psicológica se interpreta hoy día como que puede estar determinada por hechos físicos. La percepción no recibe los movimientos de la materia sino el efecto del impacto de tales movimientos sobre nucstro organismo.

Construímos el mundo a base de mensajes por los nervios del cerebro. La mente teje una impresión usando el estímulo que llega al cerebro por los nervios sensoriales, y que carece de color, temperatura, sonido y textura, cualidades que le concede el cerebro. El mundo familiar es subjetivo. La filosofía física actual es idealista. La materia deriva de la mente. Einstein, Schrodinger, Planck, Jeans, Eddington, han creado un universo sin materia, con solo estructura y relaciones explicables en términos matemáticas y lo matemático es lo mental. La mente del físico como la del psicólogo modifica el universo estudiado.

Todos los procesos mentales están causados por procesos cerebrales y éstos por procesos orgánicos, los que a su vez dependen de estímulos corporales o del medio externo. El contenido mental está determinado por el ambiente, y a la inversa. Organis- 
El ojo da la impresión simultánea de ccsas exteriores, como el oído da la sucesión de tiempo o ritmo (21). Por ello se imbrican lo espacial-simultáneo de una parte, y lo temporal sucesivo de otra. La sistemática del arte visual requiere de todos modos una correspondencia espacio-temporal, que ya existía para el artista mucho antes de que Einstein la descubriera en sus teorías de la relatividad.

El pintor moderno se halló sometido a las influencias que como una aura eléctrica impregnaban nuestro tiempo, y que habían destruído sus esquemas espaciales del mundo al demastrarle la falacía de la estabilidad del universo exterior, y su imagen o esquema corporal. Mencionemos aquí que dicho esquema corporal está en parte alimentado por el efluvio cenestésico de la sensibilidad interna, que como marea de sensaciones sensoriomotoras y viscerales, asciende, en forma de vaga resaca, hasta la esfera de la conciencia y nutre la imagen corporal. En dicha imagen, situada en las fronteras de nuestra conciencia con la subccnsciencia, se cifra la noción de nuestra personalidad física, idea ésta ya adivinada por los filósofos de la Grecia clásica.

La clave del sentido en apariencia incoherente y deforme de la pintura moderna, radica para el arte abstracto en la visión de los pintores que, al sentir roto su esquema espacial del mundo, reflejan esa hecatombe en sus cuadras, pintando un universo dislocado y de planos fracturados, sin continuidad ni solidez, en adonde el espacio y el

\section{"Jorge Puccinelli Converso"}

mo y medio son un todo. Nuestras percepciones captan la configuración de situaciones. Las cualidades de les objetos son las de toda la situación. Física y fisiologia, opinan que los estimulos cerebrales son atómicos, más el cerebro recibe impresioncs separadas, y la mente no acaba sino que comienza con el cuadro global de todo.

(21) Podríamos, como ejemplo, decir que en tiempos pasades el artista a quien se encargaban retratos de grandes señores $y$ gentes acaudaladas, captaban a menudo las enfermedades crónicas de su modelo, y gracias a ello contames hoy con una espléndida iconografía de gran valor histórico-médico. Lo que no reprodujo el pincel de los artistas clásicos, no fué sino la pirueta feliz del cuerpo humano en un bronce de Donatello, la anatomia radiante, toda explosión atlética, de Miguel Angel, o el gesto gracioso y feliz de los desnudos de Bouchard y Fragonard. Psicológicamente, el pincel de Rembrandt pudo captar la profundidad psicológica de un estado de ánimo en su autorretrato, como Franz IIals aprisionó la vida burguesa, rotunda y confiada que se estampaba en las caras de los burgomaestres que retrataba. Más nadie pudo captar el proceso dinámico de la enfermedad, que tiene un comienzo, un desarrollo $y$ un desenlace, a veces el de la cósmica tragedia de la muerte, ni tampoco el desarrollo de un proceso psicológico. 
tiempo se funden en extrañ $\alpha$ relatividad. Un mundo en donde las mulaciones se realizan a saltos quánticos, y en donde el pincel del artista parece estar movido por la misma sacudida plánclitica que agita el universo según la física atómica. El arte abstracto es la representación diagramática de la ruptura, por la física atómica, del esquema espacial en la mente del hombre moderno, $y$ en especial del artista.

A su vez, el sentido de la extraña visión que del ser humano tienen los artistas surrealistas (que combinan dicho ser humano con objetos inanimados, como Max Ernst; que lo hacen de una consistencia ingrávida, gelatinosa y transparente, como Dali; que lo presenta visto desde dentro, como Henri Moore), es una representación de la ruptura del esquema corporal que en el artista han motivado las concepciones de la biología moderna (22).

\section{4 - La reacción artística contra la influencia de la nueva Ciencia}

El artista modemo ha reflejado en su obra el impacto psicológico de la física atómica, pero, a su vez, ha luchado contra esa influen-

(22) William Hogarth (Inalysis of Bealy - Introduction), en 1753, dijo:

"Notwithstanding $I_{0}$ have inld you my design of considcring mintuly the varicty of lines which scrve to rajscthe ideas of duodirs in the mind, Gand which are undoubledly to be considered as drawn on the surfaces mily of solid or opake bodics: yet the endeavouring to conceive, as accurate an thica as is epssible, of the inside of those surfaces, if I may be allowed the extression, will be a grrat assistance to us in the pursuance of our present inquiry.

In order to my bring well understood, let cvery object unier our considiration, be imagined to have its inward contents scooped out so nircly, as to hav'c nothing of it left but a thin shell, exactly corresponding, both in its inner and onter surface, to the shape of the object itself: and let us likewise suppose this thick shell to be made up of wery fine threads, closely conterted logether, and cqually perceptible, whother the eye is supposed to observe them from without, or within; and we shall find the ideas of the two surfaces of this shell wuill naturally coincidc. The very word, shell, makes IIs seem to sec both surfaces alike.

The use of this conceit, as it may be called by some, will be scen to be very great........and the oflener we think of objects in this shell-like<manner, we shall facilitate and strengthen ont conception of any particular bart of the surface of an object we are viewing, by acpuiring thereby a more perfect knowledge of the cohole, to which it belongs: because the imagination will naturally enter into the vacant space within this shill, and there at once, as from a centre, view the whole form within, and mark the opposite corresponding parts so strongly, as to refnin the idca of the whole, and make us masters of the meaning of every vicus of the object, as we walk routhd it, and vien it from without". 
cia en cada faceta de su arte. Ante todo, para combatir la ruptura del esquema espacial de un universo desintegrado, el artista abstracto lo ha encerrado en el marco de su cuadro $y$, sobre todo, en el espacio finito -einsteniana- del universo bidimensional del cubismo. Con ello ha pretendido limitar el infinito como ha hecho la Física, y tratar de comenzar a ordenar, limitándolo, su cosmos artístico.

En segundo término, ha llevado al máximci el afán de orden, armonía y claridad, desligándose de formas, colores y ritmos supérfluos y yendo a buscar, como 'Mondrián, la suprema perfección del orden, la claridad y la calma, en su universo blanca y fijo, de líneas rectas $y$ ángulos armoniosos, en donde ha vuelto a convertirse en cosmos de armonías y claridades el universo, que convirtió en caos en la mente del artista la ruptura de los esquemas espaciales del mundo que le rodeaban.

En tercer lugar, la ruptura de los esquemas espaciales en la mente del artista moderno ha hecho que ésta deje de mirar el objeto exterior, como hizo Velázquez, para retroceder más aún y cesar hasta de mirar a la luz, como hicieron los impresionistas, para, en un praceso voluntario de ceguera psíquica progresiva (paralelo a la ceguera histérica de origen psicológico, en la que lo primero que se pierde es la forma, lo segunda la luz y el color, y lo último la noción visual de los objetos), encerrarse dentro de sí mismo. Despreciando el inestable mundo exterior de estructuras desintegradas ylleyes inciertas, el artista moderno ha creado su propie mundo de ideas, como los cubistas y pintores abstractos, o ha tendido a restaurar el orden bio-psicológico, como en la pintura surrealista.

Las figuras solitarias de da Chirico, tiritando en la espectral soledad plateada de luna de las piazzas venecianas; las figuras aisladas en desiertos lugares, de Dali, tienen el sentido de seres sumidos en la soledad cósmica en que hoy se siente el pintor, a quien arrebató la ciencia atómica su universo para dejarle en la soledad de sus ideas. De la dramatización en sus lienzos de su doble conflicto : angustia de un universo desintegrado y anheló de orden, creación y armonía en el mismo, ha brotado, como el agua de un manantial, su arte, incomprensible para muchos porque no lo correlacionan con las concepciones de la física moderna.

La ciencia ha pasado en cien años de estudiar las cosas a estudiar las sensaciones y las ideas. En la actualidad, desde el mundo fijo de las ideas, la Física intenta dominar el mundo cambiante de las cosas y las sensaciones. El arte, siguiendo análogo proceso, intenta 
desde la atalaya de las ideas crear una pintura ideológica. Porque el arte moderno trata de presentar el caos, que es para el hombre que no conoce su estructura científica el universo físico actual, intentando a la vez convertirlo en puro y armonioso cosmos con la magia de su arte.

\section{I5 - Una ojeada hacia el futuro del arte}

Puede preverse lo que el futuro reserva al arle moderno, del mismo modo que mirando el arco de piedra roto de un puente semiderruído de los que aun alzan medio arco sobre un río, es posible reconstruir, prolengándolo con la mirada, lo que sería su curva hacia la otra orilla. Mediante esa prolongación psicológica, es posible atisbar las directrices del arte del porvenir.

El artista actual ha reflejado en su obra el impacto psicológico de la ciencia atómica que le ha destrczado los esquemas - vitales para su existencia de hombre $y$ de artista, que eran su esquema espacial del universo y su imagen corporal y psíquica de sí mismo.

Mas la reacción rebelde ya se apunta en el arte de pintores como Salvadar Dali, uno de los más fanáticos surrealistas, que en su más reciente etapa se está volviendo de espaldas al arte surrealista para mostrar en sus cuadros sus Madonnas atómicas, un universo místico en donde todo flota en unal anasmagórica-levitación.

El artista moderno. Pcomon redicciónvanfela desintegración del universo por los físicos, está reconstruyendo en su obra esa universo. Escuchemos hablax a los artistas abtractos y oiremos en todos ellos la misma voz de misticismo, el mismo místico anhelo de unidad, de inefable comunión con fuerzas etemas, estables y trascendentes (23). El

(23) Escuchemos la voz de los Artistas abstractos de Norteamérica : George I. K. Morris (autor de "Suspended Discs") : Can you imagine it in any other time -an artist jast putring shapes togethor- shapes that represent nothing, eilher alone or in combinations IIc puts a frame around il, and offers it on the open market, just as a good thing to have around and look at; someting that will sjeak to you as an independent personality, and yet is very guiet". Posteriormente defiende el esfuerzo dè autocontrol y pacificación. de "harnessing of freedom" lo gue es la verdadera fuerza del artista. Compara luego un artista que pinta la Naturaleza sin seleccionar motivos, como "un pianista que se sienta sobre el teclado (Whistler) o sobro la placta". Pintar es, básicamente, una experiencia óptica. El arte tiene un impulso emocional y una textura estructural, y produce dos fucrzas opuestas como la inspiración y aspiración, requicre el impulso del pintor de activar con vida un cuadro, $y$ lo retiene con control posibilitan- 
arte abstracto contará con infinidad de técnicas, pero en el fondo de todas ellas palpita como elemento de unidad, que es su común denominador, el ansia de integración, de unidad, de solidez, de perennidad, el deseo de volver a hallar la unidad perdida del cosmos, del hombre en sí, y del hombre con el cosmos.

- Como único medio de restaurar la unidad de la materia y espíritu, hoy desintegrados, el artista ha elegido el camino de la integra-

do una actividact awe come to the sources of salvation or disaster posibilities of liberation, nozi creadora mis poderosa para el próximo cuadro.

Willem de Kuoning (autor dc "The Mail Box"). La abstracción usada en un comienzo para designar una naturaleza muerta permitió al artista no entender arte como todo lo que puede incluirse, sino como todo lo que puede elimimarse, " $I$ gate some people the idca that they could frec art from itsolf". E. artista tenunció a las cosas parta apoderarse de las idens "social ideas, to make theil objects reith, their canstructionsthe pure plastic phenomena"....... "Man's orun form in space - his body- awas a priwate prison; and that it was becanse of this imprisoning miscry - becatsse he was hingry and ovcrierked and went to a horrid place called home late at night in the rain, and his bones ached and his head was heavy- because of this very conscionsness of his own body, this sense of pathos, lhey suggest, he was overcome by the drama of a crucifixion in a painting or the lyricism of a gronp of people sitting quictly around a table drinking winc"......."Kandinsky understood "Form" as a form, like an object in the ral exarld; and an objed, he said, ewas a narrative - and so, of course, he disapproved of it . He wanted his "music without words. ZCCa C C' CLIaS kecp on yoing!".

"........Futuris/s had had a sinplet sentinem omversfoce. Everything ought to

"The argument often usct that scicuce is rcally abstract, and that painting could be like music ant, for this reason, that you cannot paint a man leaning against a lamppost, is utterly ridiculous. That space of science-lhe space of the physicists $I \mathrm{am}$ truly bored wilh by now. Their lenses are so thick that secn through them, the space gets more and more melancholy. There seems to be no end to the misery of the scientists' space. All that it contains is billions and billions of hunks of mather, hat or cold, floating around in darkness according to a great dising of aimlessuess. The stars I think about, if I could fly, I could reach in a few old fashioned days. But physicists' stars $I$ use as bullons, huttoning up curtains of cmptincss. If I stretch my arms next to the rest of myself and wonder where my fingers arohitat is all the space I need as a painter.

"Totay, some people think that the light of the atom bomb avill change the concept of painting once and for all. The eyes that actually saes the light melted out of shecr ecstasy. For one instant, evcrybody was the same color. It made angels out. of everybody. A truly Christian light, painful but forgizing".

Alexander Calder (autor de "Ilanging Mobile"): "Whink that at that time and practically ever since, the underlying sense of form in my work has becn the system of the Universe, or part thireof. For that is a vather large model to work from. 
ción, unidad y simplificación. Arte abstracto es simplificación, es despojar al universo de color y de forma, para recrearlo partienclo de la fría desnudez de la idea pura. La integración religiosa, mística, de un nuevo universo será el objetivo del nuevo arte.

What I mean is that the idea of detached bodies floatim! in space, of different sizes and densities, perhaps of different colors and temperaturis, and surrounded and intcrlarded with wisps of gascous condition, and some at rest, while others move in peculiar manners, seems to me the ideal source of form. tances.

I would have them deployed, some nearer together and some at immense disas well.

And great disparity among all the qualities of these bodies, and their motions

$A$ very exciting moment for me was at the planctarium-rihen the machine avas run fast for the purpose of explaining its opcration: a planct movid along a straight line, then suddenly made a complete loop of $360^{\circ}$ off th one side, and them aucnt off in a straighth line in its original direction.

I have chiefly limited myself to the use of black and withite as being the most disparate colors. Red is the color most opposed to both of these-and then, finally, the other primaries. The secondary colors and intermediate shades serve only to confuse and muddle the distinctucss and clarity.

When I have used spheres and discs, I have intended that they should represent more than what they just are. More or less as the carth is a sphcre, but also has some miles of gas about it, volcanocs upon it, and the moon-making circles around it, and as the sun is a sphere -but also is a source of intense heal, the effect of rwhich is felt at greal distances. A ball of 1 wood or acdisc of Inetal is rathen a dull object without this sense of something emanating from it".

Fritz Glarner (autor de "Relational Painting") : A painter should never speak because words are not the means at his command. Words cannot express visually dimension at a glance-they can only establish their own relationship in time. However, it is possible for a painter, at certain moments of his development to formulate some of the problems he is facing in the growth of his work. A painting casnot be cxplaincd. Words can only stimulate the act of looking.

To liberate form, it is necessary for the form-symbol to lose its particularity and become similar to space. To liberate form it is necessary to detcrmine space so that their structures become identical. When the form area and the space arca are of the same structure, a new aspect arises in which pure means can reveal their intrinsic expression. The differentiation between form and space has to be established by color, proportion, oppositions, etc.".

Robert Motherwell (Personage) : "One of the most striking aspects of abstract art's appcarance is her makedness, an art stripped bare. Now many rejections on the part of her artists! Whole worlds-the world of objects, the world of power and propaganda, the world of anecdotes, the world of fetishes and ancestor worship. One might almost legitimately receive the impression that abstract artist don't like anything but the act of painting.... 
Podemos anticipar, basándonos en ese mismo objetivo de unidad e integración que como clave filosófica de su estructura palpita en la nueva ciencia atómica, que el arte modemo derivará en el próximo medio siglo hacia un nuevo y laico misticismo. Una mística del arte

W'hat newe kind of mystique is this, one might ask. For make no mistake, abstract art is a form of mysticism.

Still, this is not to describe the situation very subtly. To leave out consideration of achat is bcing fut into the painting, I mean. One might truthfully say that abstract art is striptod bare of ofher things in order to intensify it, its rhythms, spatial intervals, and inlor structure. Abstraction is a process of emphasis, and emphasis vivifies life, as A. $N$. Whitchetal said.

Abstract Art is a trus mysticism-I dislike the sword- or rather a serics of mysticisms that grequ up in the historical circumstance that all mysticisms do, from a frimary sense of gulf, an abyss, a void between one's loncly self ant the world Ibstract art is an iffort to clase the woid that modern men feel. Its abstraction is its smphasis".

Stunrt Daris (autor de "Hot Still-SCapefor Six Colors") : "I think of Abstract Art in the same way I think of all Art, Past and Present. I see it as divided into taio Major calcgoric's, Objective and Subjective, Objective Art is Alsolute Art. Subjective Ant is Illustration, or communication by Symbols, Replicas, and Oblique Emotional Passes. The'y are both Art, but their Content has no Identity. Their difference cannot be defined as a difference of Idiom, becanse all Paintings have the Lazts of Design as a common denominator. Design exists, as an Idiom of Color.Space Logic, and it also cxists in an Itiom of Represcnlational Eikentesses. Objecrive Art and Subjectivi Art cxist in both ldioms. Their diferrence can only le defined in tcrms of what the Artist thinks his Purpose means-its Content as a Disign Image.

Objective Art sees the Percept of the Raal World as an Immediate Given Event, zeithout any .1bstract Term in it, But there is Consciousness of Change, of Motion, in it. The Real Object, its Image in the Idiom of Idea, and the cxicrnal Image of Idea as Design, are experienced as a simultaneons eqent in Consciousness. These thrce distinct realities arc Perceived as a single Object; a Headline on the Display-Surface of Common Sense. The conscionsness of clange cxperienced in these separate identifications is understood as the Total Form of this Object. To know this is the cxperience of its Free Accomplishment; an act anenable to Voliton. This is the Total Appearance, hence Total Content of Objective Art, Absolute. Art. Its Universal Principle is the Sense of Fredom".

"In my opiniot, all art is abstract - abstract from reality. In appearance, I sec the forms of art runing the gamul from extreme objective (evisual) to extreme subjective (stylc) reality without cacr being complctely ont or the other. For me, there exists only profound abstraction, or superficial abstraction independent of how far or how close the abstraction lics from objective or subjective reality.

In Giotto (for me the grealcst), I sec an atist noho for the first time in Western painting, has frecd himsclf of dogmatic, subjective reality it a unique way. With a perfect, subjective reality, with a profound, all-embrasing Biblical philosophy, he discovered objective reality. To him, philosophy and reality -idea and object were 
basada en las verdades de la nueva ciencia física, como el medio más decisivo de restaurar la unidad perdida de su esquema espacial del universo, $y$ de su imagen corporal, en una trascendente tentativa de suprema integración artística del hombre con el cosmos.

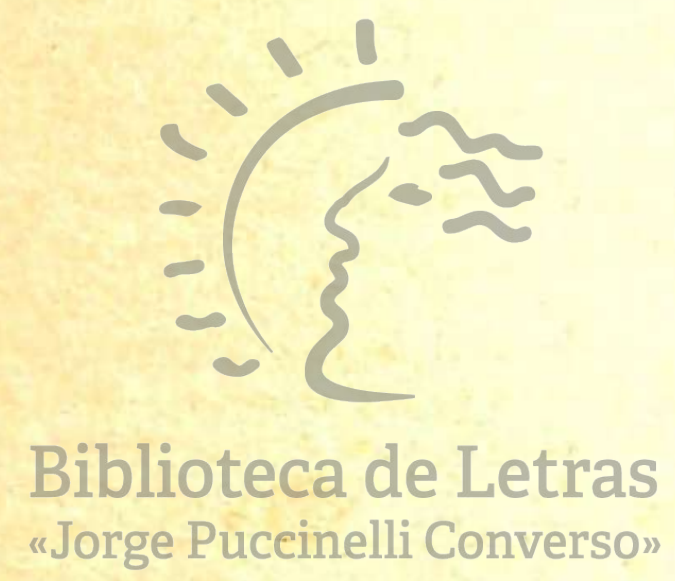

an insefiarable whole. From then on, with the continued investigation into objective reality, subjective reality lost its unity. With this loss of the mystic story of the bible and its physical and philosophical implications, the painter lost a profound, universal image something he, perhaps unconsciously, has tricd to regain throngle a new, basic, subjective reality, or through a new, all-embracing philosophy. Even El Greco's rcligious mysticism is, to me, superficial in comparison to Giollo's or oven in comparison to El Greco's own more worldly suljects.

But though the struggle betqueen subjective and objective reality probably never will be decide, Cczanne, in modern timcs proved that the same basic, mystic laws of profound alstraction (cubic, geometrical, lintear flowu) are true for the objective as well as subjective reality alike". 